\title{
Energy efficiency enhancement using dynamic voltage restorer (DVR)
}

\author{
Muhammad Murtadha Othman ${ }^{1}$, Nik Muhamad Lokman Fahmi Nek Rakami², Zulkiffli Abdul \\ Hamid $^{3}$, Ismail Musirin ${ }^{4}$, Mohammad Lutfi Othman ${ }^{5}$ \\ ${ }^{1,2,3,4}$ Faculty of Electrical Engineering, Universiti Teknologi MARA, Malaysia \\ ${ }^{5}$ Centre for Advanced Power and Energy Research and Department of Electrical and Electronics Engineering, \\ Universiti Putra Malaysia, Malaysia
}

\begin{abstract}
Article Info
Article history:

Received Jul 27, 2018

Revised Jan 12, 2019

Accepted Mar 15, 2019

\section{Keywords:}

Dynamic voltage restorer (DVR)

Energy efficiency

Harmonic

Hysteresis Voltage Control

Voltage Sag

Voltage Swell

ABSTRACT

Dynamic voltage restorer (DVR) is a device that can compensate harmonic, voltage sag and voltage swell condition that exists in a three-phase system. Other than that, DVR can also be used to enhance the energy efficiency or energy saving by reducing excessive amount of incoming power via the reduction incoming voltage at allowable limit. The DVR can inject the required voltage in the system so that the interruption of supply voltage can be compensated. The compensation of voltage supply interruption is improved based on the hysteresis voltage output of controller used in the DVR to detect the difference between reference voltage and disrupted voltage. The hysteresis voltage control mainly controlled by relays switching so that the signal can be sent to IGBT switches controller. The hysteresis voltage control and unipolar SPWM is supplied to control the IGBT switches by the DC supply for voltage interruption compensation. The unipolar SPWM technique converts the DC supply voltage into AC supplied voltage, thus making the DVR injection become easier to inject the AC voltage into the system to compensate voltage sag and voltage swell.
\end{abstract}

Copyright (c) 2019 Institute of Advanced Engineering and Science. All rights reserved.

\section{Corresponding Author:}

Muhammad Murtadha Othman, Faculty of Electrical Engineering, Universiti Teknologi MARA, 40450 Shah Alam, Selangor, Malaysia.

Email:mamat505my@yahoo.com

\section{INTRODUCTION}

Ideally, electricity should be provided efficiently and without any interruptions required or desired by utilities and users. Without the smooth continuity of electricity supply, the consumers may not receive their power demands efficiently [1-5]. However, the utilities may find it difficult to provide a clean and continuous electric supply due to the presence of harmonic distortion, voltage sag and voltage swell. The increasing usage of nonlinear loads in the industry often making the harmonic distortion level becomes critical [6-10]. Consequently, this will introduce inefficient energy consumption to the consumers.

In addition, electricity plays an important role in productivity from many industrialized countries. Therefore, the usage of power electronic components used to control the non-linear load in the industrialized countries will also be increased. However, these components are sensitive devices that are requiring a constant of voltage magnitude, voltage frequency and voltage phase [11]. They required a good power quality in order to avoid any failure in the power electronic components and electrical equipment in such a way that it will breakdown in electrical equipment and eventually damage the electrical equipment as well as slowly shorten their lifespan [12]. Therefore, this issue is not a trivial problem for countries that are developing their products in the industry. Voltage sag and swell are the main issue that may cause the power quality problem [13-17]. DVR is one of the wise solutions used to mitigate the power quality problem. It is 
able to compensate the voltage sag, voltage swell and also harmonic condition by injecting their voltage in series synchronously with the system to ensure the smoothness of power quality can be maintained [18-19]. Generally, there are three basic control strategies for a DVR such as pre-sag compensation, in-phase compensation and energy optimization compensation [20].

In pre-sag compensation, the supply voltage is consistently monitored and initiates the injection before the occurrence of voltage sag and it also able to compensate the phase shift of incoming voltage. On the other hand, the DVR with in-phase compensation will only compensate the magnitude of voltage sag. The DVR voltage is continuously in phase with the measured incoming voltage regardless the phase shift of incoming voltage. With energy optimization compensation, the voltage is injected with its phase angle in quadrature with load current to reduce the use of real power. Therefore, this strategy will reduce the energy consumption of energy storage. In a DVR controller, it uses the hysteresis voltage control to detect the disrupted incoming voltage and supplied to the Insulated Gate Bipolar Transistor (IGBTs) as switching devices for voltage-sourced converter (VSC)[21]. Specifically, DVR compensate the interruption of incoming voltage by referring to the unipolar SPWM coming from the IGBT switches.

Other than that, the DVR plays an important role in energy efficiency enhancement of a three-phase system. The energy consumption in a non-linear load can be reduced by increasing their energy efficiency via reduction of incoming voltage at allowable limit such as $200 \mathrm{~V}$ per-phase. With the reduced input voltage at the permissible limit, the load may function properly and operates at lower energy consumption. Thus, the energy efficiency of the system can be enhanced.

\section{RESEARCH METHOD}

Figure 1 shows a schematic diagram of dynamic voltage restorer (DVR) connected in series with the sensitive load in a distribution system. The DVR contains of voltage-sourceFigu converter (VSC), hysteresis voltage control, a booster transformer and also passive filter used to filter any harmonic component exists in the system. The DVR will inject a three-phase of AC voltage in series synchronously with the supplied voltage for the occurrence of voltage sag or voltage swell. This signifies that whenever the quality of supplied voltage is interrupted or distorted, the DVR can restore the quality of the voltage at the load side by controlling the voltage amplitude, phase angle and frequency of voltage.

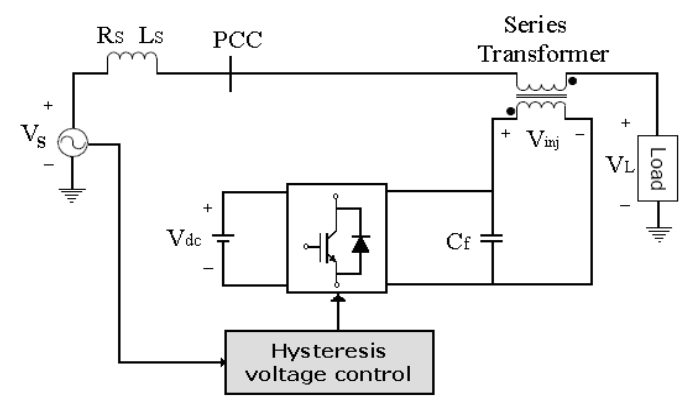

Figure 1. Basic principle of dynamic voltage restorer

The ensuing explanation represents the operation of DVR. Firstly, the DVR will receive a signal from point representing as the current situation of incoming supply voltage. Secondly, the DVR will detect the incoming supply with power quality problem condition converted as a small signal coming from point $\mathrm{B}$ and comparison is made between incoming voltage supply signal $\left(\mathrm{V}_{\text {Line }}\right)$ having power quality problem and reference voltage in order for the hysteresis voltage controller to operate and mitigate the waveform segment of incoming voltage supply having the power quality problem. This operation is performed by the DVR indicated by label $\mathrm{C}$ in Figure 2. In particular, the difference between reference voltage and incoming voltage supply having power quality problem will transmit as a difference signal to perform the switching in relays for later use in mitigating and compensate the power quality problem incurred in the incoming voltage supply. The hysteresis switching relays will instruct the operation of IGBT switches labeled as D to produce the unipolar SPWM signal from DC supply voltage into AC supply voltage [22]. Lastly, the IGBT switches will inject its converted supply voltage into the system to compensate the voltage sag and swell in the system through the three-phase isolation transformer labeled as E. 


\subsection{Voltage supply}

The parameters are adjusted in the source to supply the desired output voltage and is referring to label A in Figure 2. The positive-sequence parameters are set to 508VL-L for voltage supply, $0^{\circ}$ for the phase and $50 \mathrm{~Hz}$ for the frequency. The voltage must be set to $508 \mathrm{Vrms}$ in order to obtain $415 \mathrm{VL}-\mathrm{L}$ obtained based on the rms value is $508 \mathrm{Vrms} \times \sqrt{ }(2 / 3)=415 \mathrm{VL}-\mathrm{L}$. The time variation is set to "Amplitude" and the type of variation is set to "Table of time-amplitude pairs" so that the time value setting can be enabled. The amplitude value is in per unit and the time values is adjusted to the desired output values in order to display the percentage of voltage sag and swell as well as its duration. The fundamental and/or harmonic generation is enabled to include the effect of harmonic in the voltage supply yielding to the unbalanced condition of voltage sag or swell.

\subsection{Three-phase V-I measurement}

The three-phase voltage and current supply is measured by using the three-phase V-I measurement indicated as label B shown in Figure 2. The three-phase V-I measurement is responsible to observe the performance of DVR in mitigating the voltage sag or swell that occurs in the three-phase system. The threephase V-I measurement is also installed at the load side to measure and monitor the interrupted load voltage and current compensated by the dynamic voltage restorer. Figure 2 shows a schematic diagram of DVR designed and successfully executed in the Simulink software.

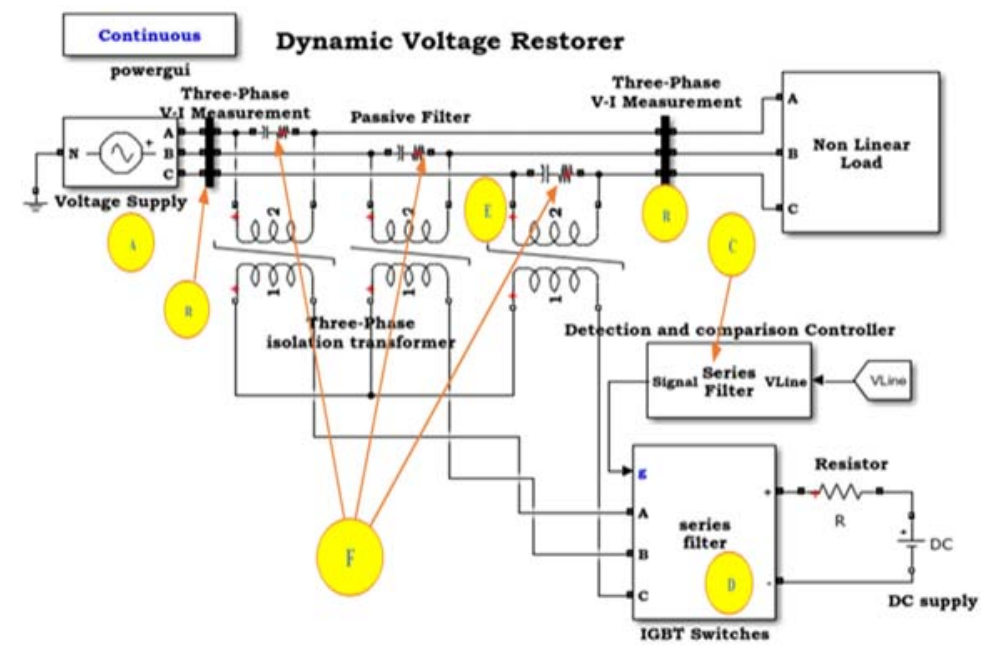

Figure 2. Simulink diagram of dynamic voltage restorer

DVR controllerError! Reference source not found. The DVR controller labeled as C in Figure 2 is used to detect the voltage sag and voltage swell which will then compared with the fixed reference voltage specified in the controller [23]. A detail circuit of DVR controller can be seen in Figure 4 whereby it consists of incoming voltage, reference voltage generator, detection and comparison circuits, hysteresis voltage control. The reference voltage generator is used to provide a smooth sinusoidal three-phase waveform of $415 \mathrm{~V}_{\mathrm{L}-\mathrm{L}}$. A smooth sinusoidal waveform of three-phase voltage is produced from the equation embedded in the block diagram and is set as the fixed reference voltage. The incoming voltage sag or swell is obtained from the line voltage labeled as $V_{\text {Line }}$ in Figure 4. The obtained incoming voltage sag or swell is compared with the fixed reference voltage at the comparator labeled as G. The comparison between fixed reference voltage and the incoming voltage sag or swell is made to produce a difference or error signal required by the relay or hysteresis voltage control [24]. Subsequently, the difference or error signal is sent to the IGBT switches so that the switching can be performed in respond to convert from DC voltage to AC voltage under the unipolar SPWM formation at a particular time to compensate at a certain time segment of incoming supply having voltage sag or voltage swell.

\subsection{IGBT switches}

The difference or error signal is sent by the relay or hysteresis controller for an immediate operation of IGBT switches labeled as D in Figure 2.

Int J Pow Elec \& Dri Syst, Vol. 10, No. 3, Sep 2019 : 1308 - 1316 
In Figure 3, there are six IGBT switches connected in a three-phase bridge connection. The difference or error signal will drive the IGBT switches to produce the unipolar SPWM in discrete-time waveform at point I to inject and compensate the voltage sag or swell occurred in the system [25]. The voltage magnitude of unipolar SPWM can reach up to $700 \mathrm{~V}$ originated from the DC supply voltage at point 1 and point 2. This implies the IGBT switches convert the DC voltage supply into AC output voltage of unipolar SPWM.

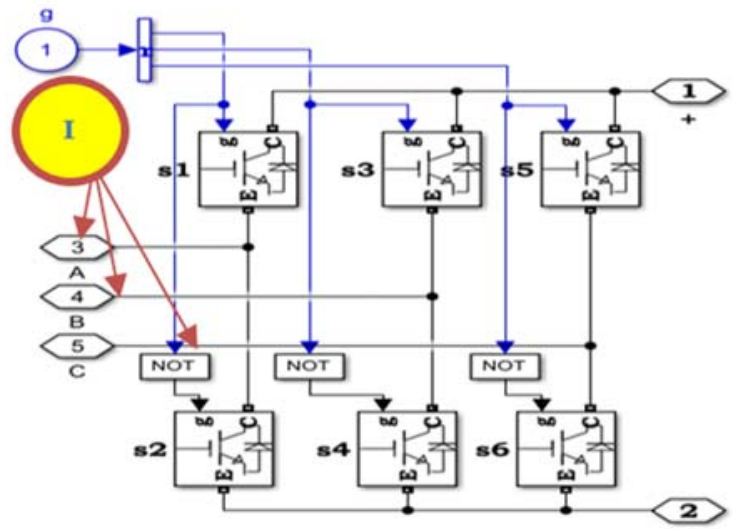

Figure 3. IGBT switches

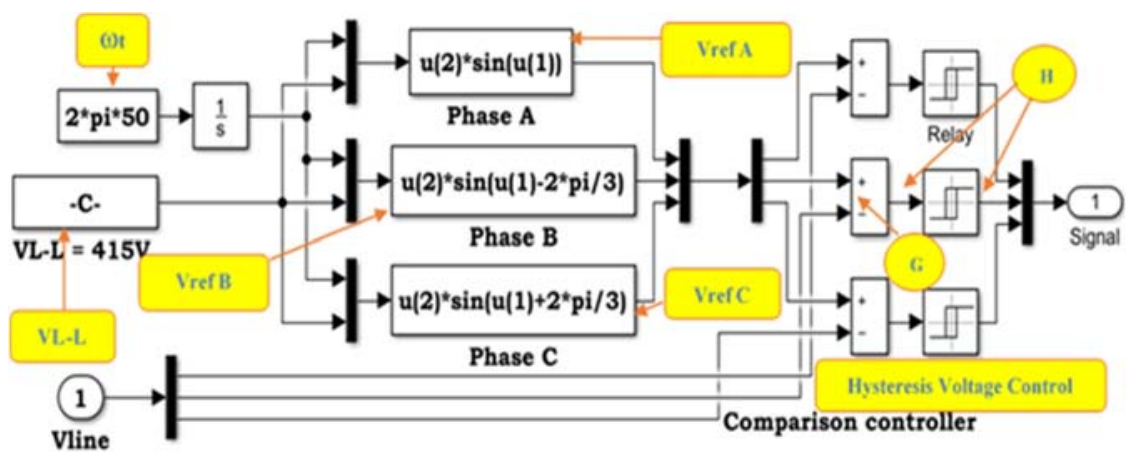

Figure 4. DVR controller circuit

\subsection{Three-phase isolation/booster transformer}

The three-phase isolation or booster transformer is connected in series with the three-phase system and it is labeled as E in Figure 2. It is used to inject the AC voltage of unipolar SPWM waveform into the system so that the incoming voltage sag or swell can be compensated. The secondary-side of transformer is in wye connection and the primary-side of transformers is connected in series with the three-phase system.

The fixed value of parameters is set into the transformer so that the desired output waveform can be obtained. The nominal power and frequency are $4000 \mathrm{VA}$ and $50 \mathrm{~Hz}$, respectively. It is specified for the transformer and it is depending on the KVA rating of loading condition. The primary (1) and secondary (2) side of transformer is composed with the parameters setting of voltage, resistance, and inductance that is $508 \mathrm{~V}, 0.02$ p.u. and 0.02 p.u., respectively. The saturation characteristic, core loss resistance and initial flux are set in accordance to the standard type of three-phase isolation transformer available in the market. The three-phase isolation transformer received the unipolar SPWM of discrete-time waveform to compensate the distorted signal of an AC sinusoidal continuous-time waveform happened in the three-phase system.

\subsection{Three-phase isolation/booster transformer}

The passive filter labeled as B in Figure 2 is comprised of resistor and capacitor used to filter the harmonic components originated from the voltage compensation injected by the three-phase isolation

Energy efficiency enhancement using dynamic voltage restorer (DVR) (Muhammad Murtadha Othman) 
transformer. The RC branch type consisting with resistor and capacitor is selected in such a way to operate the passive filter. The resistance and capacitance values are set as $1 \Omega$ and $100 \mu \mathrm{F}$, respectively for the RC branch type of passive filter.

\section{RESULTS AND ANALYSIS}

The operating performance of three-phase dynamic voltage restorer (DVR) has been carried-out on a case study of three-phase system consisting with $8.14 \mathrm{kVA}$ rating of power supply and $7.56 \mathrm{kVA}$ rating of loading condition shown in Figure 2. The DVR is responsible to mitigate the three power quality problems of voltage sag, voltage swell and harmonic. It is worthwhile to mention that the main task of DVR controller is to produce the difference or error signal between the reference voltage and interrupted incoming voltage. The error signal is then received by the IGBT switches to produce the AC unipolar SPWM. The AC unipolar SPWM is transferred to the three-phase isolation transformer to convert and compensate the distorted part of incoming voltage. Figure 5 shows the fixed reference voltage of $415 \mathrm{~V}$ taken from Vref A, Vref B and Vref C in DVR controller circuit shown in Figure 4.

Figure 6 shows the difference between the fixed voltage reference and distorted incoming voltage at 0.1 second until 0.15 second taken from Vline and Vref in Figure 4. The comparison is made between the two waveforms to initiate the operation of DVR controller. The incoming voltage distortion is one of the power quality problems that may instigate ineffective operation of load hence shorten the lifespan performance. As a result, the comparison between the reference voltage and distorted incoming voltage may yield to hysteresis signal and difference or error signal at the input and output of point $\mathrm{H}$ in Figure 4, respectively. The hysteresis signal and difference or error signal are shown in Figure 7 and the duration for both signals to operate is between 0.1 second to 0.4 second depending to the duration of distorted incoming voltage discussed beforehand.

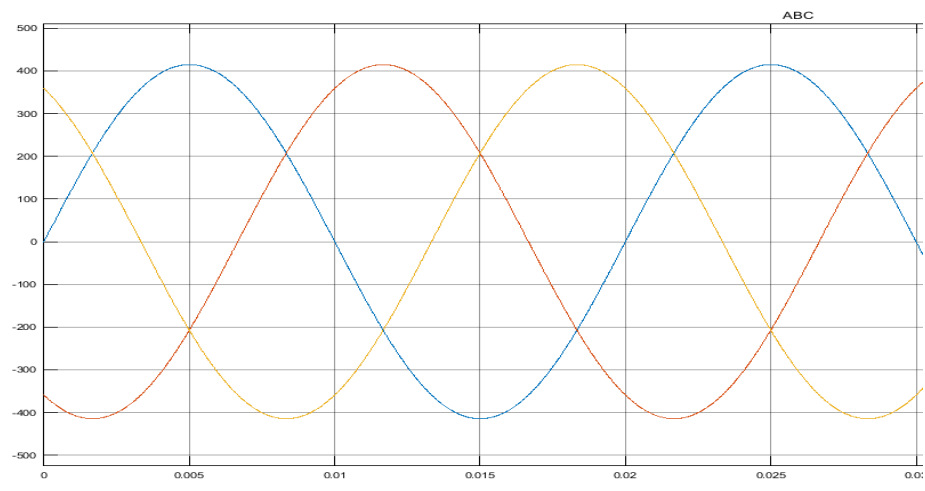

Figure 5. Three-phase fixed reference voltage.
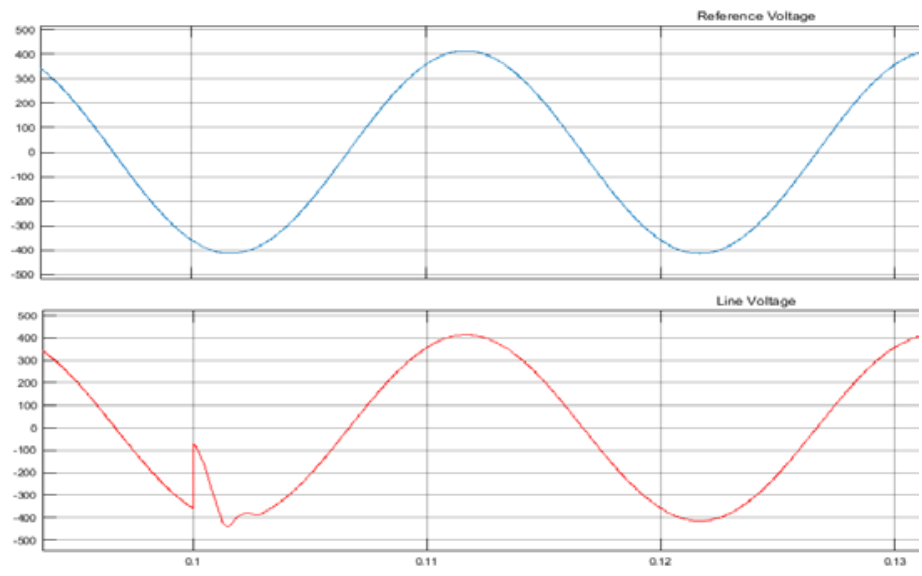

Figure 6. Comparison between the (a) fixed reference voltage, and (b) distorted incoming voltage waveform.

Int J Pow Elec \& Dri Syst, Vol. 10, No. 3, Sep 2019 : 1308 - 1316 

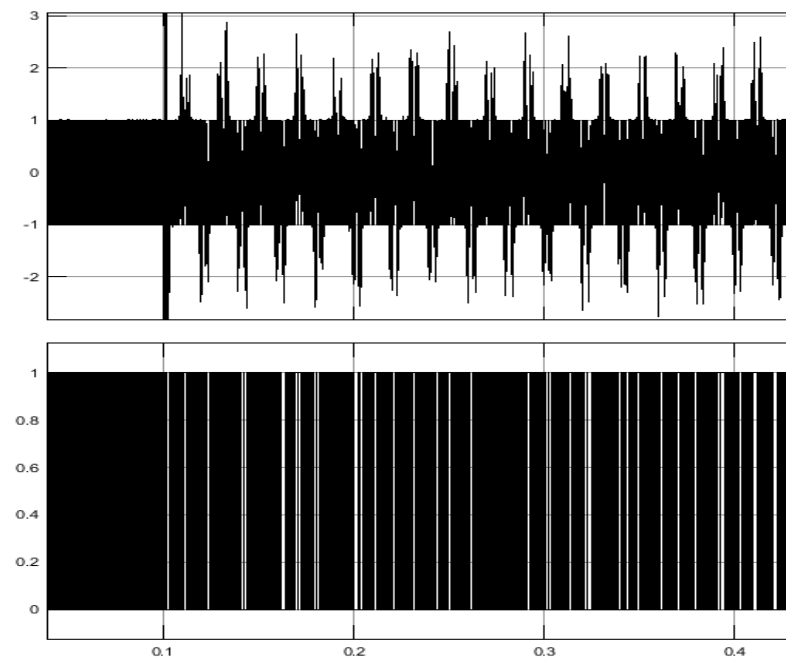

Figure 7. (a) Hysteresis signal, and (b) difference or error signal subject to the comparison between the fixed reference voltage and distorted incoming voltage.

The width for every pulse of difference or error signal is representing the magnitude distortion of voltage. The difference or error signal is obtained from the switching relay and is used to trigger the IGBT switches to convert from DC voltage supply and then inject the AC unipolar SPWM. By referring to Figure 3 , the difference or error signal is transferred via point $\mathrm{G}$ of IGBT switches circuit. The three-phase AC unipolar SPWM is shown in Figure 8 and these waveforms are obtained from point I in Figure 3. Eventually, the IGBT controller will inject the AC unipolar SPWM into the three-phase system merely to compensate the magnitude distortion of AC incoming voltage.

Further analysis to investigate effective performance of DVR is done for two different cases of voltage sag and swell. The first analysis is done based on the $80 \%$ of voltage sag happened at duration 0.1 second to 0.15 second shown in Figure 9(a). Hence, the three-phase incoming voltage is reduced to 0.2 p.u. during the sagging condition. Therefore, the DVR controller detect the 0.2 p.u. of incoming voltage sag and compared it with the fixed reference voltage of $1.0 \mathrm{p}$.u. that eventually driven the IGBT switches to inject AC unipolar SPWM to compensate 0.8 p.u. remaining magnitude of voltage sag shown in Figure 9(c). The improved incoming voltage subject to the compensation made by the DVR is shown in Figure 9(b).

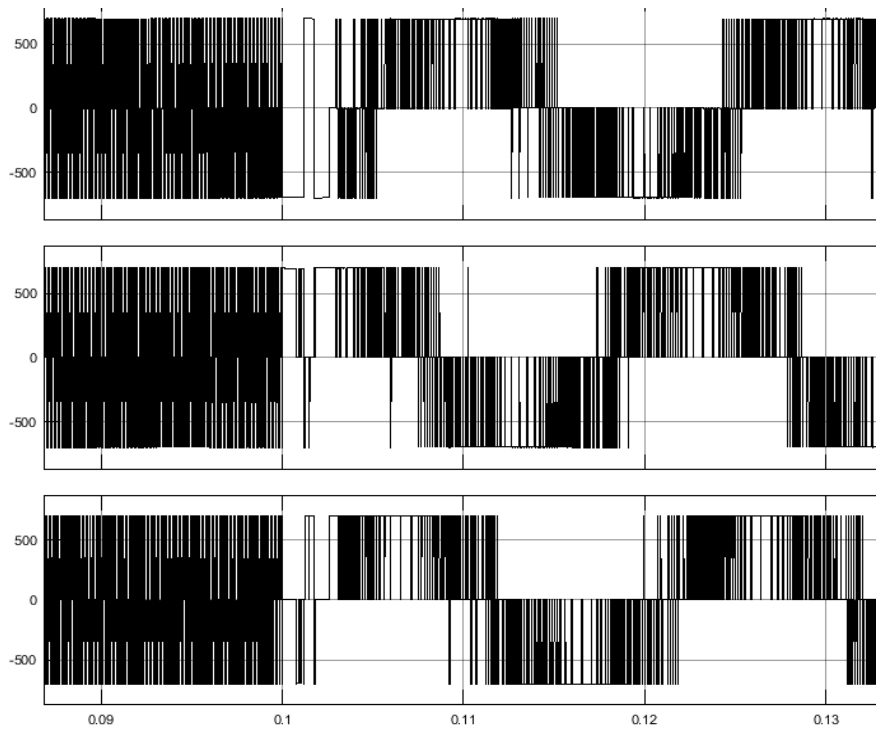

Figure 8. The AC unipolar SPWM of the IGBT controller for (a) Phase A, (b) Phase B, and (c) Phase C.

Energy efficiency enhancement using dynamic voltage restorer (DVR) (Muhammad Murtadha Othman) 

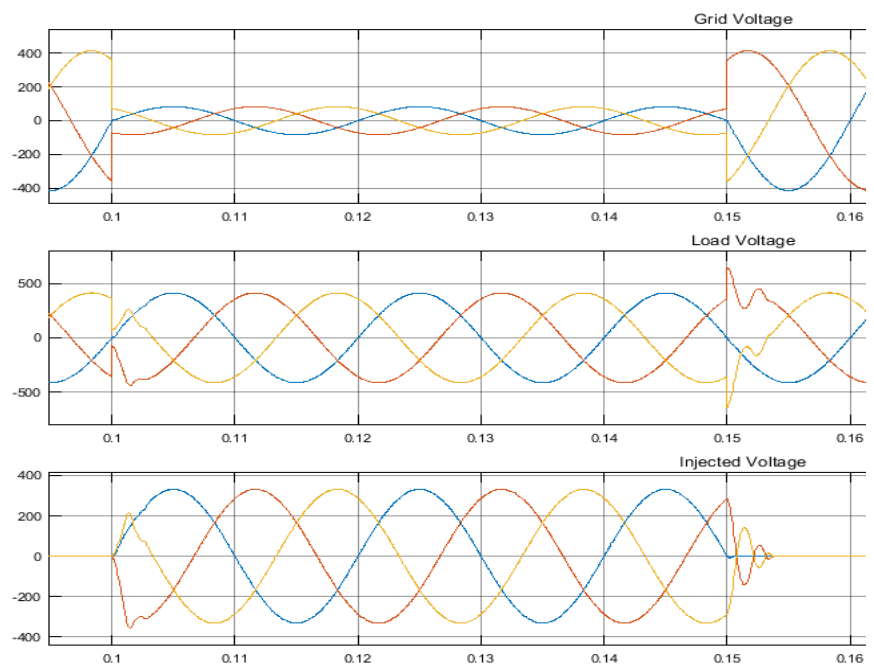

Figure 9. DVR performance at $80 \%$ of voltage sag (a) before compensation, (b) after compensation, and (c) voltage compensation.

The robustness of DVR is also investigated and verified based on the cases of $80 \%$ in the occurrence of voltage swell shown in Figure 10(a). The duration of $80 \%$ of voltage swell is 0.1 second to 0.15 second. The DVR inject AC unipolar SPWM to compensate 0.8 p.u. remaining magnitude of voltage swell to the three-phase system for compensation as shown in 18(c). The improved version of incoming voltage compensation done by the DVR can be observed in 18(b). The results proof that the DVR is capable to effectively mitigate the voltage swell at any level of percentage.
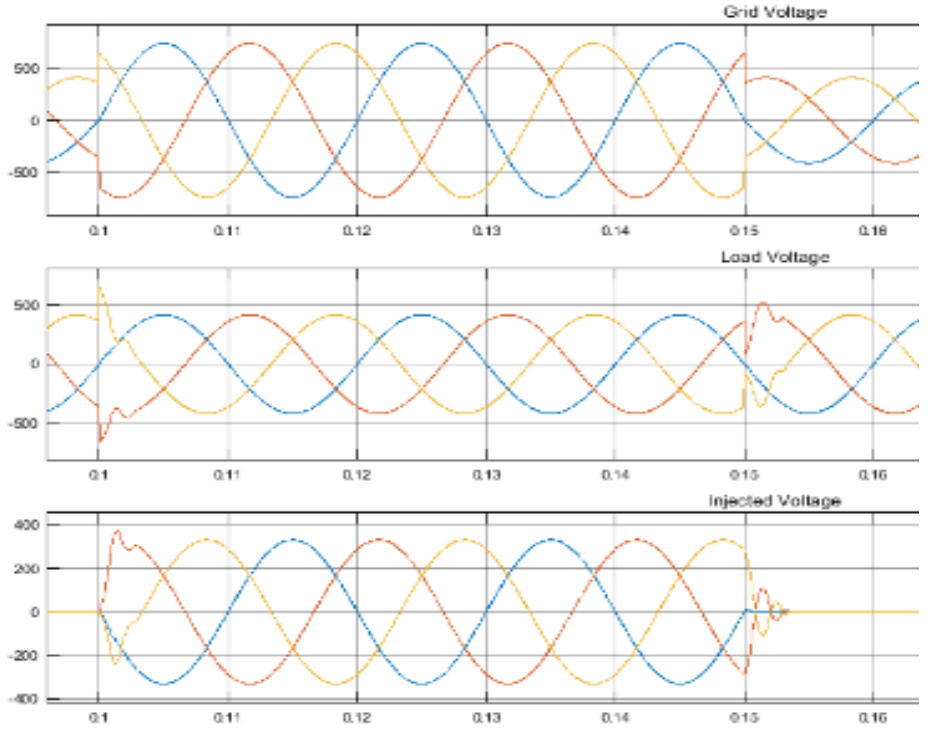

Figure 10. DVR performance at $80 \%$ of voltage swell (a) before compensation, (b) after compensation, and (c) voltage compensation.

Figure 11(a) shows the unbalanced incoming voltage waveform caused by the harmonic injected from the source. The DVR controller will operate the IGBT switches to produce AC unipolar SPWM for mitigating the unbalanced incoming voltage condition caused by injected harmonic. Figure 11(c) shows the $\mathrm{AC}$ voltage injected from the three-phase isolation transformer and provides the mitigated unbalanced 
incoming voltage as shown in Figure 11(b). Finally, the DVR capable to reduce the total harmonic distortion (THD) at every phase from $20.62 \%$ to the range of $0.21 \%$ to $0.23 \%$. The results are depicted and summarized in Table 1. Thus, the DVR is also performed effectively in producing a smooth sinusoidal waveform of threephase incoming voltage subsequent to the harmonic mitigation. By mitigating the harmonic, the power losses in the system will be reduced. Rather than mitigating the voltage sag, voltage swell, and unbalanced voltage condition caused by the harmonic condition, the DVR can also be used for energy saving purposes by reducing the real power and reactive power at allowable level injected to the three-phase system. Table 2 shows the results of energy saving corresponding to the incoming real and reactive powers subject to the reference voltage of $415 \mathrm{~V}$ and $346.5 \mathrm{~V}$ set by the DVR. The results show that the incoming real and reactive powers are reduced from $2244 \mathrm{~W}$ and $803.9 \mathrm{VAR}$ to $1874 \mathrm{~W}$ and $671.5 \mathrm{VAR}$ in accordance to the reduction of reference voltage from $415 \mathrm{~V}$ to $346.5 \mathrm{~V}$ specified at the DVR. The reference voltage is reduced to $346.5 \mathrm{~V}$ because it is an permissible limit for the operation of any electrical equipments. The incoming power saving is obtained from $16.49 \%$ and $16.47 \%$ for the reduction of real power and reactive power, respectively performed by the DVR. This signifies that the voltage reduction performed by the DVR is capable to produce a power saving to the incoming of the three-phase system.

Table 1. Total harmonic distortion for every phase before and after compensation using DVR

\begin{tabular}{ccc}
\hline Voltage & THD before compensation & THD after compensation \\
\hline Phase A & 0.2062 & 0.002104 \\
Phase B & 0.2062 & 0.002178 \\
Phase C & 0.2062 & 0.002343 \\
\hline
\end{tabular}

Table 2. Power at $415 \mathrm{~V}$ and $346.5 \mathrm{~V}$ of reference voltage

\begin{tabular}{cccc}
\hline Power & Vref $=415 \mathrm{~V}$ & Vref $=346.5 \mathrm{~V}$ & Power Saving Percentage (\%) \\
\hline Real Power (W) & 2244 & 1874 & 16.49 \\
Reactive Power (VAR) & 803.9 & 671.5 & 16.47 \\
\hline
\end{tabular}
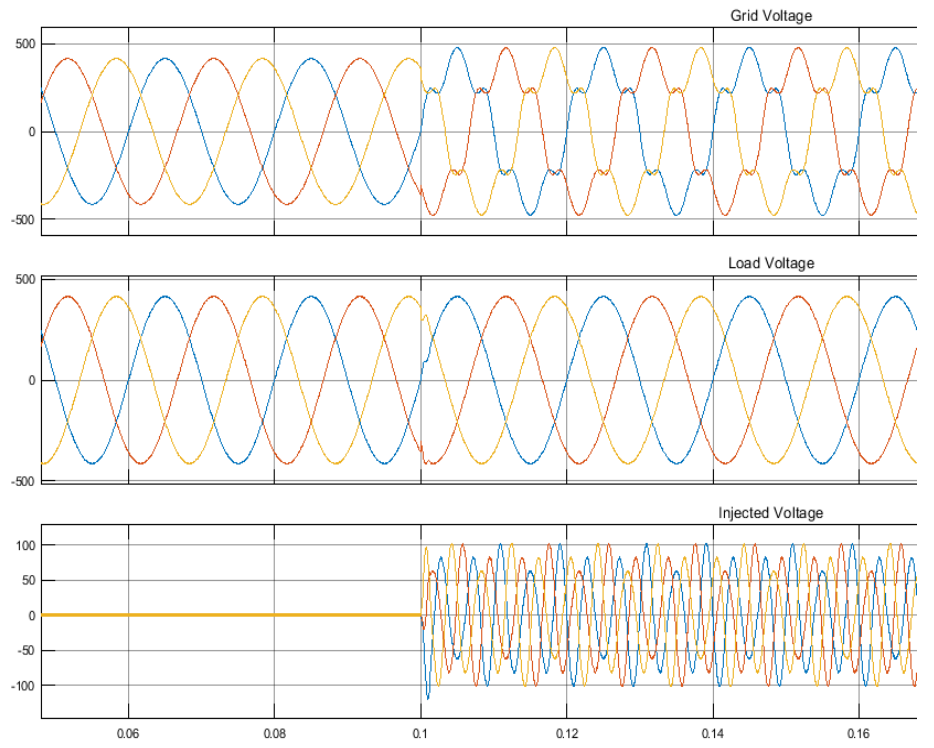

Figure 11. DVR performance at unbalanced voltage (a) before compensation, (b) after compensation, and (c) voltage compensation.

\section{CONCLUSION}

In this study, the DVR plays many important roles in enhancing power quality and also enhancing energy efficiency. The hysteresis voltage control was used in this study as a DVR controller to learn how the controller operates during the voltage sag, voltage swell, unbalanced voltage occurrence occurs in the system. In addition, by reducing the excessive amount of incoming voltage, it can also decrease the power consumption at the incoming side. The fixed reference voltage was reduced at permissible limit in order to

Energy efficiency enhancement using dynamic voltage restorer (DVR) (Muhammad Murtadha Othman) 
reduce the power consumption at the incoming side. By doing this operation, the DVR will assume the system condition as a voltage swell condition that occurs in the system and will try to reduce the excessive amount of incoming voltage to compensate the voltage swell condition. Therefore, the cost of power consumption of the non-linear load is reduced and the energy efficiency of the load is enhanced.

\section{ACKNOWLEDGEMENT}

This research was supported by the Long-Term Research Grant (LRGS), Ministry of Education Malaysia for the program titled "Decarbonisation of Grid with an Optimal Controller and Energy Management for Energy Storage System in Microgrid Applications" with project code 600-IRMI/LRGS 5/3 (001/2019). The authors would also like to acknowledge The Institute of Research Management \& Innovation (IRMI), Universiti Teknologi MARA (UiTM), Shah Alam, Selangor, Malaysia for the facilities provided to support on this research.

\section{REFERENCES}

[1] N. D. Tleis, Power Systems Modelling and Fault Analysis. 2008.

[2] K. Hinton, J. Baliga, M. Feng, R. Ayre, and R. S. Tucker, "Power consumption and energy efficiency in the internet," IEEE Network, vol. 25, no. 2, pp. 6-12, 2011.

[3] H. Zhao, Q. Wu, S. Hu, H. Xu, and C. N. Rasmussen, "Review of energy storage system for wind power integration support," Applied energy, vol. 137, pp. 545-553, 2015.

[4] S. Kakran, and S. Chanana, "Smart operations of smart grids integrated with distributed generation: A review," Renewable and Sustainable Energy Reviews, vol. 81, pp. 524-535, 2018.

[5] Y. Kuang, Y. Zhang, B. Zhou, C. Li, Y. Cao, L. Li, and L. Zeng, "A review of renewable energy utilization in islands," Renewable and Sustainable Energy Reviews, vol. 59, pp. 504-513 2016.

[6] N. Ciurro, "Harmonics in industrial power systems," EC M Electr. Constr. Maint., 2009.

[7] A. Kalair, N. Abas, A. R. Kalair, Z. Saleem, and N. Khan, "Review of harmonic analysis, modeling and mitigation techniques," Renewable and Sustainable Energy Reviews, vol. 78, pp. 1152-1187, 2017.

[8] N. R. Kalaskar, and R. Holmukhe, "Report on Power Compensation and Total Harmonic Distortion level Analysis," International Journal of Electrical and Computer Engineering, vol. 6, no. 6, pp. 2577, 2016.

[9] D. Fallows, S. Nuzzo, A. Costabeber, and M. Galea, "Harmonic reduction methods for electrical generation: a review," IET Generation, Transmission \& Distribution, vol. 12, no. 13, pp. 3107-3113, 2018.

[10] R. P. B. da Silva, R. Quadros, F. P. Santilio, L. C. P. da Silva, B. C. Carvalho, and A. B. de Vasconcellos, "Effects of Electronic Loads on Electrical Measurements, Power Quality and Billing," Journal of Control, Automation and Electrical Systems, vol. 28, no. 5, pp. 654-663, 2017.

[11] F. C. De la Rosa, Harmonics and Power Systems. 2006.

[12] J. Arrillaga, "Power quality," in Systems, Controls, Embedded Systems, Energy, and Machines, 2017.

[13] M. H. J. Bollen, Understanding power quality problems: Voltage sags and interruptions. 1999.

[14] T. Kang, S. Choi, A. S. Morsy, and P. N. Enjeti, "Series voltage regulator for a distribution transformer to compensate voltage sag/swell," IEEE Transactions on Industrial Electronics, vol. 64, no. 6, pp. 4501-4510, 2017.

[15] R. Kapoor, R. Gupta, S. Jha, and R. Kumar, "Boosting performance of power quality event identification with KL Divergence measure and standard deviation," Measurement, vol. 126, 134-142, 2018.

[16] K. Thirumala, T. Jain, and A. C. Umarikar, "Visualizing time-varying power quality indices using generalized empirical wavelet transform," Electric power systems research, vol. 143, pp. 99-109, 2017.

[17] A. Sharma, B. S. Rajpurohit, and S. N. Singh, "A review on economics of power quality: Impact, assessment and mitigation," Renewable and Sustainable Energy Reviews, vol. 88, pp. 363-372, 2018.s

[18] J. Arrillaga, B. C. Smith, N. R. Watson, and A. R. Wood, Power system harmonic analysis. 2013.

[19] P. Li, L. Xie, J. Han, S. Pang, and P. Li, "A new voltage compensation philosophy for dynamic voltage restorer to mitigate voltage sags using three-phase voltage ellipse parameters," IEEE Transactions on Power Electronics, vol. 33, no. 2, pp. 1154-1166, 2018.

[20] P. Kumari and V. K. Garg, "Simulation of Dynamic Voltage Restorer Using Matlab to Enhance Power Quality in Distribution System," Int. J. Eng. Res. Appl., vol. 3, no. 4, pp. 1436-1441, 2013.

[21] A. Kazemi and A. Azhdast, "Implementation of a control strategy for dynamic voltage restorer(DVR) and dynamic voltage compensator(DVC)," 2009 IEEE/PES Power Syst. Conf. Expo. PSCE 2009, no. Dvc, pp. 1-6, 2009.

[22] H. Ezoji, A. Reza, M. Shahverdi, A. Ghatresamani, and M. Hosein, "Hysteresis Voltage Control of DVR Based on Unipolar PWM," in Applications of MATLAB in Science and Engineering, InTech, 2011.

[23] D. K. Chaturvedi, Modeling and simulation of systems using MATLAB® and simulink ${ }^{\circledR} .2017$.

[24] F. A. L. Jowder, "Modeling and simulation of Dynamic Voltage Restorer (DVR) based on hysteresis voltage control," IECON Proc. (Industrial Electron. Conf., pp. 1726-1731, 2007.

[25] S. Rajesh, M. K. Mishra, S. M. Ieee, and K. Sridhar, "Design and Simulation of Dynamic Voltage Restorer ( DVR ) Using Sinusoidal Pulse Width Modulation ( SPWM )," pp. 317-322, 2010.

Int J Pow Elec \& Dri Syst, Vol. 10, No. 3, Sep 2019: 1308 - 1316 